\title{
Does imagery impede or facilitate transfer of learning?
}

\author{
JANAT FRASER PARKER, LEE BROWNSTON, and ILEANA RUIZ \\ Florida International University, Miami, Florida
}

\begin{abstract}
Stimulus imagery level (pictures vs. words) and instructions to subjects (neutral vs. interactive imagery) were orthogonally manipulated in order to investigate their joint effect on transfer. One hundred forty-four students learned three lists conforming either to an A-B, A-D, A-F transfer paradigm or to an A-B, C-D, E-F transfer paradigm. With neutral instructions, there was no evidence of significant negative transfer for pictures or words. With imagery instructions, there was significant negative transfer for words but not for pictures. Discussion focused on the failure to find reduced associative interference in the typical paradigm (words with imagery instructions) used in popular mnemonic techniques.
\end{abstract}

At the beginning of the 1970s, there was an upsurge in research on mnemonic techniques that subsequently subsided in the 1980s. Cornoldi (1988) suggested that the reason for the decline might be that researchers began to suspect that the usefulness of the techniques was severely limited. The Second Conference on the Practical Aspects of Memory addressed many of the concerns regarding mnemonics research (see, e.g., Cornoldi, 1988; Pressley \& McDaniel, 1988) and recommended further research. The present study focuses on one particular problem common to several mnemonic techniques-the use of the same stimuli (e.g., pegs and loci) across numerous lists of to-be-remembered items.

It has been established that stimulus imagery (see, e.g., Paivio, 1965) and instructions to use interactive visual images (see, e.g., Bower, 1970) are each positively related to the speed of learning single lists of paired associates. Because imagery influences the associational process, one may question whether imagery could overcome the negative effects of using the same stimuli in the learning of repeated lists. Such a situation actually conforms to the traditional A-B, A-D negative transfer paradigm. This is the typical scenario involved when individuals employ a mnemonic technique such as the method of pegs or the method of loci, in which the same pegs and loci are used repeatedly across numerous to-be-remembered lists. Advocates of mental imagery strategies (see, e.g., Paivio, 1971, p. 337; Roth, 1961) often claim that the same stimulus items may be used repeatedly with an imagery mnemonic without interference. However, there is little or no evidence to support such an assertion. Studies in which the imagery value of stimuli has been manipulated consistently fail to demonstrate a reduction in negative trans-

Correspondence should be addressed to J. F. Parker, Department of Psychology, Florida International University, University Park, Miami, FL 33199. fer as a function of stimulus imagery (Parker \& Bass, 1975; Postman \& Gray, 1979; Tatum, 1976). Parker and Bass found comparable levels of negative transfer in the A-B, A-D paradigm for both pictures and words. Likewise, Tatum, using the same paradigm, confirmed this finding in a comparison of concrete and abstract words. Using the A-B, A-Br paradigm, Postman and Gray also found similar levels of negative transfer for concrete and abstract words.

When imagery has been manipulated by instructions to subjects rather than by varying stimulus-imagery level, once again no effect on transfer has been observed. Using the A-B, A-D paradigm, Wood (1967) found comparable levels of negative transfer with both verbal- and imagery-mediation instructions. Similar failures to reduce negative transfer with imagery instructions have been observed by Lowry (1974), Mueller and Pickering (1977), and Tor and Freund (1979). Each of the latter studies tried to maximize the possibility of observing differences by manipulating the placement of imagery instructions. However, whether the instructions occurred prior to List 1 alone (Lowry, 1974), prior to List 2 alone (Tor \& Freund, 1979), or alternated between imagery and verbal mediation from List 1 to List 2 (Mueller \& Pickering, 1977), levels of negative transfer remained similar to the results with neutral instructions.

Thus, it can be concluded that neither imagery instructions nor stimulus imagery, considered singly, has been shown to alter negative transfer. In none of the previous studies, however, was stimulus imagery manipulated when the subjects were also using an imagery mediational strategy on both original learning and transfer. If, as suggested by mnemonists, imaginal coding is less subject to interference than is verbal coding, the combination of imagery instructions with pictures should maximize the possibility of observing a reduction in negative transfer. It was further hypothesized that this reduction might become more salient when the potential for interference is increased by 
having subjects learn a third set of responses to the same set of stimuli. Furthermore, such a multilist design more closely approximates the typical application of mnemonic techniques such as the method of pegs and loci.

The present study was designed to examine negative transfer in the A-B, A-D, A-F paradigm under both imagery and neutral instructions. Pictures and their noun labels were chosen as stimulus materials in order to equalize for semantic content.

\section{METHOD}

\section{Design and Subjects}

The subjects were 144 Florida International University undergraduates. The experimental design comprised eight groups representing the factorial combination of two levels of stimulus imagery (pictures and words), two transfer paradigms (A-B, A-D, A-F, and A-B, C-D, E-F), and two types of instructions (imagery and neutral). Assignment to groups was in blocks of 8 , with 1 subject from each group per block. The students were tested individually and were assigned to groups in the order of their appearance in the laboratory.

\section{Materials}

The learning materials were lists of 10 paired associates, with either pictures or their labels as stimuli and concrete words as responses. There were three sets of response materials that were used to generate nine basic lists. Under all transfer conditions, each of the lists was used twice as the first, second, and third tasks.

The picture stimuli were line drawings of familiar objects selected from a pool of pictures prepared by Csapo (1971). The 30 pictures chosen had a $96 \%$ rating with respect to consistency of labeling, and their word labels were uniformly high in concreteness (mean $C=6.91$ ), imagery (mean $\mathrm{I}=6.54$ ), and meaningfulness (mean $m=6.65$ ), as determined by Paivio, Yuille, and Madigan (1968). The concrete words used as responses were comparable (mean $C=6.83$, mean $I=6.54$, and mean $m=7.26$ ). The stimuli and responses were approximately equated on Thorndike-Lorge (1944) frequencies.

\section{Procedure}

All of the subjects were presented three paired-associate lists by the study/test method on a Stowe memory drum at a 3-sec rate with a 3-sec intertrial interval. The pairs were presented in four different orders on the study trials and four other orders on the test trials. The first two lists were learned to a criterion of one perfect trial, and the third list was learned to a criterion of one perfect trial and at least four total trials. The interval between lists was $3 \mathrm{~min}$.

Prior to presentation of the first list, half of the subjects received instructions that encouraged them to employ an imagery mediation strategy. For each stimulus-response pair, they were told to form a mental image in which the stimulus term and the response term were in interaction. The remaining subjects received neutral instructions that did not refer to mental imagery but simply asked subjects to learn a list of pairs by studying each pair as it appeared. Shortened versions of the relevant instructions were presented prior to Lists 2 and 3.

\section{RESULTS}

The mean numbers of trials to criterion for all three lists are presented in Table 1 . Separate $2 \times 2 \times 2$ analyses of variance (stimulus imagery $\times$ transfer paradigm $\times$ instructions) were conducted for each list.

\section{First-List Learning}

In agreement with other investigators, imagery instructions produced faster learning than did neutral instructions $[F(1,136)=12.84, p<.001]$. There was no interaction of stimulus imagery $\times$ instructions $(F<1)$.
Table 1

Mean Number of Trials to Criterion for All Three Lists as a Function of Stimulus Imagery, Instructions, and Paradigm

\begin{tabular}{cccccccccc}
\hline & \multicolumn{3}{c}{ Imagery } & Instructions & & \multicolumn{3}{c}{ Neutral Instructions } \\
\cline { 2 - 7 } & \multicolumn{2}{c}{ Pictures } & \multicolumn{2}{c}{ Words } & & \multicolumn{2}{c}{ Pictures } & \multicolumn{2}{c}{ Words } \\
\hline Lists & C-D & A-D & C-D & A-D & & C-D & A-D & C-D & A-D \\
\hline 1 & 2.67 & 2.33 & 2.83 & 3.27 & & 3.67 & 3.33 & 3.78 & 4.05 \\
2 & 2.83 & 2.89 & 2.44 & 4.67 & & 3.39 & 3.28 & 3.28 & 3.50 \\
3 & 2.72 & 2.61 & 2.78 & 4.50 & & 2.33 & 2.94 & 3.50 & 3.89 \\
\hline
\end{tabular}

The typical finding of picture superiority over words just missed significance $[F(1,136)=3.50, p<.10]$. This is not too surprising, since the slower rate of presentation in this study $(3 \mathrm{sec})$ may have restricted the range over which trials to criterion could vary (2.33-4.04), perhaps attenuating the apparent differences between stimulus imagery levels.

\section{Second-List Learning}

The main effects of stimulus imagery and instructions failed to reach significance $[F(1,136)=1.83, p>.05$, and $F<1$, respectively]. Performance in the C-D paradigm was superior to that in the A-D paradigm $[F(1,136)$ $=4.66, p<.05]$. There was a significant transfer para$\operatorname{digm} \times$ stimulus imagery interaction, with word stimuli showing greater negative transfer $[F(1,136)=5.10, p<$ $.05]$, and a significant transfer paradigm $\times$ instructions interaction, with imagery instructions showing greater negative transfer $[F(1,136)=3.83, p<.05]$. Although the three-way interaction of stimulus imagery $\times$ instructions $\times$ transfer paradigm just missed significance $[F(1,136)=$ $2.74, p<.10$ ], it suggests that the major evidence for negative transfer occurs for words as stimuli under imagery instructions.

\section{Third-List Learning}

The main effects of transfer paradigm and stimulus imagery were both significant $[F(1,136)=6.80, p<.01$, and $F(1,136)=16.41, p<.001$, respectively]. Negative transfer was still evident, and performance with picture stimuli was reliably superior to that with word stimuli. There were no main effects of imagery instructions, and none of the two-way interactions was significant. However, the three-way interaction of stimulus imagery $\times$ imagery instructions $\times$ transfer paradigm was now significant $[F(1,136)=4.22, p<.05]$. A test of the simple main effects of that interaction showed significant negative transfer only for the word stimuli under imagery instructions $[F(1,136)=11.87, p<.001]$. The trend that was evident in List 2 resulted in significance in List 3.

\section{DISCUSSION}

A casual examination of the groups receiving imagery instructions appears to support the hypothesis that imagery instructions in conjunction with pictures are effective in eliminating negative transfer. However, there was also no evidence of negative transfer with either pictures or words for groups receiving neutral instructions. This finding is at variance with several other studies (Parker \& Bass, 1975; Postman \& Gray, 1979; Tatum, 1976) in which negative transfer was found. An 
inspection of the rates of presentation of these studies reveals that a faster rate $(2 \mathrm{sec})$ was used, whereas the present study used a slower rate $(3 \mathrm{sec})$ to permit image formation. Similarly, Tor and Freund (1979) employed a slower rate $(4 \mathrm{sec})$ in their second experiment and found no evidence for negative transfer for either concrete or abstract words. However, they did find negative transfer for both stimulus types in Experiment 1, in which a 2-sec rate was used. As with Tor and Freund (1979), it appears that lengthening the study rate of presentation does not differentially reduce the amount of negative transfer but rather allows both stimulus-imagery groups to overcome associative interference.

In light of the failure to find significant negative transfer in the groups receiving neutral instructions, the absence of negative transfer with the combination of pictures and imagery instructions loses its impact. On the other hand, the fact that the group receiving word stimuli with imagery instructions does show significant negative transfer gains in importance. For the word group, perhaps the imagery-interaction instructions encourage the construction of a highly integrated and stable association on List 1 that is difficult to break down on later lists. This explanation is consistent with Paivio's (1971) mediation theory and with Bower's (1970) hypothesis that interactive imagery instructions produce strong relational associations. For the picture group, it is possible that this association is easier to break down on later lists, since the stimulus picture is presented as a separate static unit and thus the compound image is already forced apart.

The implication of this finding of potent negative transfer is critical with respect to unsubstantiated claims that the same visual images may be used repeatedly with success in such various popular mnemonic techniques as the method of loci and pegs, among others. Clearly, further study of interference effects in these memory improvement techniques per se is in order.

\section{REFERENCES}

BOWER, G. H. (1970). Imagery as a relational organizer in associative learning. Journal of Verbal Learning \& Verbal Behavior, 9, 529-533.

CoRNoldi, C. (1988). Why study mnemonics? In M. M. Gruneberg, P. E. Morris, \& R. N. Sykes (Eds.), Practical aspects of memory: Current research \& issues (pp. 397-402). New York: Wiley.

CSAPO, K. G. (1971). Stimulus attributes, presentation rate, and coding in short-term memory. Unpublished doctoral dissertation, University of Western Ontario, London, ON, Canada.
Lowry, D. H. (1974). The effects of mnemonic learning strategies on transfer, interference, and 48-hour retention. Journal of Experimental Psychology, 103, 16-20.

Mueller, J. H., \& PiCkering, J. P. (1977). Concreteness and encoding instructions in paired-associate transfer. Bulletin of the Psychonomic Society, 9, 1-4.

PaIvio, A. (1965). Abstractness, imagery and meaningfulness in pairedassociate learning. Journal of Verbal Learning \& Verbal Behavior, 4, 32-38.

Paivio, A. (1971). Imagery \& verbal processes. New York: Holt, Rinehart \& Winston.

Paivio, A., Yuille, J. C., \& Madigan, S. (1968). Concreteness, imagery and meaningfulness values for 925 nouns. Joumal of Experimental Psychology Monographs, 76(1, Pt. 2).

PARKer, J. F., \& BASs, D. (1975). Pictures versus words as stimuli in paired-associate transfer. American Journal of Psychology, 88, 635-642.

Postman, L., \& GRAY, W. D. (1979). Does imaginal encoding increase resistance to interference? American Journal of Psychology, 92, 215-233.

Pressley, M., \& McDaniel, M. A. (1988). Doing mnemonics research well: Some general guidelines and a study. In M. M. Gruneberg, P. E., Morris, \& R. N. Sykes (Eds.), Practical aspects of memory: Current research \& issues (pp. 409-414). New York: Wiley.

Roth, D. M. (1961). Roth memory course. Santa Monica, CA: Motivation.

TATUM, B. C. (1976). Stimulus imagery effect in associative learning: Differentiation or mediation? Journal of Experimental Psychology: Human Learning \& Memory, 2, 252-261.

THORNDIKE, E. L., \& LORGE, I. (1944). The teacher's wordbook of 35,000 words. New York: Teacher's College, Columbia University Press.

TOR, P. B., \& FREUND, J. S. (1979). Encoding variability with imagery instructions in paired-associate transfer. Bulletin of the Psychonomic Society, 13, 12-14.

Wood, G. (1967). Mnemonic systems in recall. Journal of Educational Psychology, 58(Pt. 2, Whole No. 645), 1-27.

(Manuscript received June 14, 1993.) 